\title{
Radiation Protection
}

\section{An Investigation of Awareness on the Fukushima Nuclear Accident and Radioactive Contamination}

Jeong Chul $\mathrm{Ha}^{*}$ and Youngju Song*

*Department of Consumer Safety, Korea Consumer Agency, Chungcheongbuk-do, Republic of Korea

\begin{abstract}
Background: The objective of this study was to investigate Korean people's awareness about impact of the Fukushima nuclear power plant accident in Japan and radioactive contamination caused by it.

Materials and Methods: The respondents of the survey were 600 adults who resided in the Seoul metropolitan area.

Results and discussion: The survey results show that the majority of respondents were concerned about impact of radiation leakage that might have an effect on our environment. They were worried about radioactive contamination of foodstuffs, particularly fishery products and preferred to acquire information through TV(49.8\%) or the Internet(31.3\%). Meanwhile, respondents mentioned that the information on the Fukushima nuclear accident and radioactive contamination had not been sufficient and they didn't know well about the follow-up measures of the government on the accident. Most respondents answered that information on radioactive contamination levels and safety of foods and environment was most needed.

Conclusion: The results of this study could be useful to enhance awareness on radioactivity and improve risk communication on nuclear power plant accidents.
\end{abstract}

Keywords: Awareness, Fukushima, Nuclear accident, Radioactive, Contamination

Correspondence to Jeong Chul $\mathrm{Ha}$ hjc1010@kca.go.kr

This is an Open-Access article distributed under the terms of the Creative Commons Attribution Non- Commercial License (http://creativecommons.org/licenses/by-nc/3.0) which permits unrestricted non-commercial use, distribution, and reproduction in any medium, provided the original work is properly cited. 


\title{
후쿠시마 원전사고 및 방사능 오염에 대한 인식조사
}

\author{
하정철", 송영주 \\ "한국소비자원 소비자안전국 \\ 2015년 10월 13일 접수 / 2015년 11월 26일 1차 수정 / 2015년 12월 24일 채택
}

연구배경: 본 연구는 일본 후쿠시마 원전사고 이후 원전사고 및 방사능 오염에 대한 우리 국민들의 인식도를 확인하기 위한 목적으로 진행되었다.

재료 및 방법: 설문조사는 수도권에 거주하는 성인 600명을 대상으로 하였다.

결과 및 논의: 연구 결과, 대다수 국민들은 일본 원전사고로 인한 방사능 누출이 우리나라에 영향을 미치고 있다고 우려하였다. 식품, 특히 수산물의 방사능 오염에 대한 우려가 높았고, 선호하는 정보 취득원은 TV( $49.8 \%)$ 와 인터넷 매체(31.3\%)였다. 한편 다수의 국민들은 일본 원전사고 및 방사능 오염 정보가 충분히 제공되지 않았고, 원전사고 이 후 우리 정부의 대응조치를 잘 모르고 있는 것으로 나타났다. 또한 국민 대다수가 식품·환경 등의 방사능 오염 정도 와 안전성에 대한 정보제공 강화가 가장 중요한 것으로 인식하고 있었다.

결론: 본 연구 결과는 향후 방사능에 대한 올바른 인식 확립과 방사능 안전사고 리스크커뮤니케이션을 위한 유용한 자료로 활용될 수 있을 것으로 기대된다.

중심어 : 인식, 후쿠시마, 원전사고, 방사능, 오염

\section{1. 서론}

2011년 3월 11일 일본 동북부 지방 앞바다에서 발생 한 대규모 지진과 지진해일(쓰나미)로 인해 후쿠시마 현 에 위치해 있던 원자력 발전소의 원자로가 폭발하여 다 량의 방사능 물질이 누출되는 사고가 발생하였다. 사고 이후 국민들은 방사능 물질에 직접 노출되는 것뿐만 아 니라 방사능에 오염된 식품을 통한 인체 피폭을 우려하 게 되었다. 이에 정부는 방사능 물질에 오염된 식품의 유통을 차단하기 위해 일본산 식품의 수입을 통제하거나 식품 방사능 검사를 강화하였고[1], 홈페이지 등을 통해 그 결과를 공개하고 있다[2]1). 하지만 정부의 이러한 조 치에도 불구하고 방사능 물질에 오염된 먹거리로 인해 건강을 해칠 수 있다는 국민들의 불안감은 줄어들지 않 았고, 일본 원전사고와 관련한 루머들이 인터넷 등을 통 해 무분별하게 확산되면서 일본산 식품의 수입을 반대하 거나 소비를 기피하는 현상들이 나타났다[3, 4].

방사능 오염 식품의 섭취로 인한 내부피폭은 대개 낮 은 선량의 방사선 노출로, 건강에 영향을 미치는지 여부 는 과학적으로 명확하게 결론이 나지 않은 상황이다[5]2).

\section{책임저자 : 하정철, hjc1010@kca.go.kr}

충청북도 음성군 맹동면 용두로 54 , 한국소비자원 소비자안전국, 27738

1) Ministry of Food and Drug Safety(MFDS). Information for radioactivity safety management. 2015. Available at: www.mfds.go. kr/index.do?mid=975.

2) World Health Organization(WHO). Archive of Japan nuclear concerns
이러한 불확실성은 부정적인 위험 인식의 요인으로 작용 하고, 원전사고 및 방사능과 관련하여 입증되지 않은 정 보의 유통과 전달 매체들의 정보 불일치 등을 유발해 과 도한 불안감을 형성시킬 수 있다[6, 7]. 이러한 부정적 인 식과 불안감 증가 요인들을 감소시키고 국민들의 인식 변 화를 도모하기 위한 방법으로 리스크커뮤니케이션의 필 요성과 중요성이 강조되고 있다. 리스크커뮤니케이션은 개인, 조직, 다양한 이해관계자들이 정보 및 의견을 상호 교환하는 전략적 과정을 의미하며, 이러한 과정은 사회적 갈등을 완화하고 불필요한 사회적 비용을 저감시키는 효 과를 가져 올 수 있다. 리스크커뮤니케이션의 활성화를 위해서는 다양한 계층을 대상으로 한 인식조사가 선행되 어야 하며[8], 이러한 조사결과의 면밀한 분석을 통해 국 민들이 쉽게 이해할 수 있는 수준의 정확한 정보를 생산 하고 효과적인 창구를 이용해 쌍방향으로 소통되어야 할 것이다.

따라서 본 연구에서는 방사능에 대한 기본 지식, 지식 수준의 자각 정도, 원전사고 영향 정도, 정보 취득 경로 등을 분석함으로써 우리 국민들의 인식 수준을 파악하 고, 일본 원전사고와 방사능에 대한 올바른 정보 전달과 인식제고를 위한 효과적인 리스크커뮤니케이션 방안의 기초자료를 마련하고자 하였다.

frequently asked questions. 2011. Available at: www.who.int/hac/crises/ jpn/faqs_archive/en/. 


\section{2. 재료 및 방법}

방사능 관련 효과적인 리스크커뮤니케이션 방안 마련 이라는 연구목적 달성을 위해 설문조사를 진행하였고, 조사는 2014년 9월 15일부터 9월 30일까지 수도권에 거 주하는 만 20세 이상 성인 600명을 대상으로 1:1 면접 설문 방식으로 응답자가 직접 설문지를 작성하도록 하 였다.

설문지는 방사선과 방사능에 대한 국민들의 지식수준 및 자각 정도, 후쿠시마 원전사고와 방사능 오염에 대한 인식, 후쿠시마 원전사고와 방사능 관련 정보 수집경로 및 신뢰도, 향후 후쿠시마 원전사고에 대한 정보제공 방 향 및 해결과제 등 4 개 항목으로 분류한 후 총 14 개 문 항으로 구성하였다. 개별 설문 문항은 선행연구 등을 참 고로 하였고, 완성된 설문지는 원자력 및 방사능 전문가 와 사회과학 전문가에게 의뢰하여 구성과 문항의 타당성 을 검토 받았다[9-12]. 수집된 자료는 SPSS19.0 통계프로 그램을 사용하여 분석하였다.

\section{3. 결과 및 논의}

\section{1 조사대상의 일반적 특성}

조사대상의 일반적 특성은 Table 1과 같다. 전체 응답 자는 600명이며, 남자 295명(49.2\%), 여자 305명(50.8\%) 이다. 연령별로는 20-29세 109명(18.2\%), 30-39세 135명 (22.5\%), 40-49세 122명(20.3\%), 50-59세 111명(18.5\%), 60-69세 66명(11.0\%), 70세 이상이 57명(9.5\%)이었다.

\section{2 방사선과 방사능에 대한 지식수준 및 자각 정도}

응답자 본인의 지식수준에 대한 자각 정도를 알아보 기 위한 '방사선과 방사능에 대하여 알고 있는가'라는 문 항에 대해 '매우 잘 알고 있다'는 70명(11.7\%), '알고 있 다'는 255명(42.5\%), '모른다'는 253명(42.2\%), '전혀 모 른다'는 응답자는 22 명 $(3.7 \%)$ 으로 나타났다.

방사선과 방사능에 대한 실제 지식 정도를 알아보기 위해 '방사선과 방사능은 같은 뜻이다', '방사선은 일종의 에너지원이다', '병원에서 건강검진에 이용하는 X-ray는
Table 1. Characteristics of Respondents

\begin{tabular}{cccc}
\hline \multirow{2}{*}{ Characteristic } & N & $\%$ \\
& Male & 600 & 100 \\
\hline \multirow{3}{*}{ Gender } & Female & 305 & 49.2 \\
& $20-29$ & 109 & 50.8 \\
& $30-39$ & 135 & 18.2 \\
\multirow{3}{*}{ Age } & $40-49$ & 122 & 22.5 \\
& $50-59$ & 111 & 20.3 \\
& $60-69$ & 66 & 18.5 \\
& $70-$ & 57 & 11.0 \\
\hline
\end{tabular}

방사선이다' 등 10 개 세부 문항을 제시하여 '그렇다', '그 렇지 않다', '모른다'로 답하도록 하였다. 각 문항별로 올 바른 답변이면 10점, 잘못된 답변 또는 '모른다'로 응답 한 경우는 0 점으로 처리하여 총 100점으로 환산하여 평 가한 결과, 평균 56.7 점 $(\mathrm{SD}=19.4)$ 으로 나타나 방사선과 방사능에 대한 지식수준이 높지 않았다. 금번 연구의 질 문 문항과는 차이가 있으나 2011년 선행연구에서도 우 리 국민들의 방사성 물질 관련 지식과 이해도는 전반적 으로 낮다는 사실을 확인할 수 있다[9]. 해당 연구에서는 지식수준과 이해도가 낮은 상황에서 정확하지 않은 정보 가 확산될 경우 실제보다 불안감이 증가될 수 있다고 지 적하고 있다.

지식수준을 100점 만점으로 점수화 한 후 상위그룹 71-100점, 중상위그룹 61-70점, 중하위그룹 41-60점, 하 위그룹을 0-40점으로 분류해본 결과, 상위그룹은 114 명 (19.0\%), 중상위그룹 94명(15.7\%), 중하위그룹 225명 (37.5\%), 하위그룹 167명(27.8\%)으로 나타났다.

방사능에 대한 지식수준이 높은 상위그룹은 지식수준 에 대한 자각 정도는 '잘 모른다(45.6\%)'로 답변한 비율이 높아 본인의 지식수준을 실제 보다 낮게 평가하는 경향을 보였고, 중상위그룹의 경우 실제 지식수준과 자기 인식수 준이 유사한 경향을 보였다. 반면 중하위그룹과 하위그룹 은 '잘 알고 있다'라고 답변한 비율이 각각 $48.4 \%, 34.1 \%$ 로 실제보다 자기 지식수준을 높게 평가하는 경향을 보였 고, 그 결과는 Table 2 와 같다.

Table 2. An Accurate Understanding and Perception on Knowledge of Radiation and Radioactivity

\begin{tabular}{|c|c|c|c|c|c|c|}
\hline \multirow{2}{*}{ Classification } & & \multicolumn{4}{|c|}{ Perception on knowledge } & \multirow{2}{*}{ Total } \\
\hline & & Know well & Know & Don't know well & Don't know & \\
\hline \multirow{2}{*}{$\begin{array}{c}\text { Upper rank } \\
\text { (71-100 points) }\end{array}$} & $\mathrm{N}$ & 20 & 41 & 52 & 1 & 114 \\
\hline & $\%$ & 17.5 & 36.0 & 45.6 & 0.9 & 19.0 \\
\hline \multirow{2}{*}{$\begin{array}{l}\text { Mid-upper rank } \\
\text { (61-70 points) }\end{array}$} & $\mathrm{N}$ & 13 & 48 & 31 & 2 & 94 \\
\hline & $\%$ & 13.8 & 51.1 & 33.0 & 2.1 & 15.7 \\
\hline \multirow{2}{*}{$\begin{array}{l}\text { Mid-low rank } \\
\text { (41-60 points) }\end{array}$} & $\mathrm{N}$ & 22 & 109 & 91 & 3 & 225 \\
\hline & $\%$ & 9.8 & 48.4 & 40.4 & 1.3 & 37.5 \\
\hline \multirow{2}{*}{$\begin{array}{l}\text { Low rank } \\
\text { (0-40 points) }\end{array}$} & $\mathrm{N}$ & 15 & 57 & 79 & 16 & 167 \\
\hline & $\%$ & 9.0 & 34.1 & 47.3 & 9.6 & 27.8 \\
\hline \multirow{2}{*}{ Total } & $\mathrm{N}$ & 70 & 255 & 253 & 22 & 600 \\
\hline & $\%$ & 11.7 & 42.5 & 42.2 & 3.7 & 100.0 \\
\hline
\end{tabular}


Table 3. Awareness on the Impact of the Fukushima Nuclear Accident (\%)

\begin{tabular}{|c|c|c|c|c|c|c|}
\hline & $\begin{array}{l}\text { Strongly } \\
\text { disagree }\end{array}$ & Disagree & Agree & $\begin{array}{l}\text { Strongly } \\
\text { agree }\end{array}$ & $\begin{array}{c}M \\
(4 \text { points) }\end{array}$ & $\mathrm{SD}$ \\
\hline $\begin{array}{l}\text { The radiation leak by the Fukushima nuclear power plant } \\
\text { accident has had an effect on environment and people in } \\
\text { Korea }\end{array}$ & 0.3 & 7.0 & 53.8 & 38.8 & 3.31 & 0.61 \\
\hline $\begin{array}{l}\text { The domestic foods are safe from radioactive } \\
\text { contamination after the nuclear power plant accident }\end{array}$ & 13.8 & 58.7 & 25.2 & 2.3 & 2.16 & 0.68 \\
\hline $\begin{array}{l}\text { The foods imported from Japan are safe from radioactive } \\
\text { contamination after the nuclear power plant accident }\end{array}$ & 37.3 & 55.7 & 6.5 & 0.5 & 1.70 & 0.61 \\
\hline
\end{tabular}

Table 4. Concerned Issues after the Fukushima Nuclear Accident

\begin{tabular}{lcc}
\hline & N & \\
\hline Direct human exposure by radioactive contaminated rain and air & 97 & 30 \\
Radioactive contamination of tap water and drinking water & 23 & 5.4 \\
Radioactive contamination of agricultural products by soil pollution & 294 & 17.1 \\
Radioactive contamination of fishery products & 103 & 92.9 \\
Import of radioactive contaminated agro-fishery products and foods & 556 & 1.5 \\
Other & Total & 550.0 \\
\hline
\end{tabular}

Table 5. Actions for Responding to the Fukushima Nuclear Accident in Daily Life

\begin{tabular}{lcc}
\hline I avoid getting wet if possible & $\mathrm{N}$ & 149 \\
I wear a mask and cap when going outside & 45 & 14.5 \\
I wash my hands or take a shower after going out & 180 & 4.4 \\
I take medicine or health supplements which have been shown to be effective in emission & 18 & 17.5 \\
of radionuclides & 85 & 3.8 \\
I eat seaweed or kelp which contain high levels of natural iodine & 353 & 196 \\
I refrain from eating imported foods from Japan & 34.3 \\
I avoid or cut down on eating fishery products & 19.1 \\
Other & 0.2 & 1,028 \\
\hline
\end{tabular}

\section{3 후쿠시마 원전사고와 방사능 오염에 대한 인식}

후쿠시마 원전사고로 인해 본인 및 국내에 미치는 영 향에 대한 인식도를 파악하기 위해 5 개 문항을 활용하였 다. '후쿠시마 원전사고로 인한 방사능 누출이 우리나라 에 영향을 미치고 있다'라는 문항에 대해서는 '매우 그렇 다'와 '그런 편이다'라고 답변한 응답자가 각각 233 명 (38.8\%), 323명(53.8\%)으로 대부분을 차지하였고, '그렇 지 않은 편이다' 또는 '전혀 그렇지 않다'는 응답자는 $7.3 \%$ 에 그쳤다. 주로 남성보다는 여성들이, 평균연령이 낮아질수록, 방사능에 대한 지식수준이 높을수록 원전사 고 방사능 누출의 영향을 우려하고 있었다(Table 3).

'매우 그렇다'와 '그런 편이다'라고 답한 응답자 556명 (92.6\%)을 대상으로 후쿠시마 원전사고로 인한 방사능 물질 누출로 '어떤 부분이 가장 우려되는지'를 질의한 문 항에서는 '어패류 등의 수산물 오염'이 $52.9 \%$ 로 가장 높 았고, '오염된 농수산물 및 식품 수입' $18.5 \%$, '방사능 비 또는 대기에 의한 직접적 인체 노출' $17.4 \%$ 등의 순으로 나타났다(Table 4). 이와 같은 결과는 원전사고 직후, 그 리고 최근 태풍의 영향으로 방사능 물질이 바다로 유출
되면서 수산물에 대한 방사능 오염의 우려가 높아진 점 이 원인으로 보인다.

식품의 방사능 오염 위험에 대한 인식을 알아보기 위 해 '후쿠시마 원전사고 이후 우리나라 국내산 식품이 방 사능 오염으로부터 안전하다고 생각하는가?'라는 문항에 '전혀 안전하지 않다' 또는 '안전하지 않은 편이다'고 답 한 응답자는 전체의 $72.5 \%$, '안전한 편이다' 또는 '매우 안전하다'는 응답자는 $27.5 \%$ 였다. '후쿠시마 원전사고 이 후 국내에 수입되는 일본산 식품이 방사능 오염으로부터 안전하다고 생각하는가?'라는 문항에는 '전혀 안전하지 않다' 또는 '안전하지 않은 편이다'라고 답한 응답자는 전 체의 $93.0 \%$, '안전한 편이다' 또는 '매우 안전하다'는 응 답자는 $7.0 \%$ 였다. 따라서 일본산 수입식품의 방사능 오 염에 대한 우려도가 더 높았지만, 국내산 식품에 대한 불안감 역시 높은 비율을 나타냈다(Table 3). 국내 영향 에 대한 인식도와 마찬가지로 남성보다 여성이, 평균연 령이 낮을수록, 방사능에 대한 지식수준이 높을수록 국 내산 식품과 일본 식품의 방사능 오염에 대한 불안감이 높았다. 이는 가사와 육아 비중이 높은 여성들이 남성들 에 비해 식품안전 문제에 민감하고, 20-30대 연령대와 
지식수준이 높을수록 방사선 피폭 위험에 대한 지식 습 득 기회가 상대적으로 많았을 것이고 이 과정에서 일부 과장된 정보에 보다 빈번하게 노출된 것이 원인으로 추 정된다.

'후쿠시마 원전사고 이후 본인 및 가족 건강을 위하여 어떠한 조치를 취한 적이 있는가라는 문항에 전체의 $87.0 \%$ 가 별도의 조치를 취한 적이 있다고 답변하였다. Table 5와 같이 구체적으로 어떤 조치를 취하였는지를 살펴본 결과, '일본산 식품의 섭취를 자제한다' $34.3 \%$, '수산물의 섭취를 줄이거나 하지 않는다' $19.1 \%$, '외출 후 손을 씻거나 샤워를 한다' $17.5 \%$, '가급적 비를 맞지 않는다' $14.5 \%$ 순으로 나타났다. 원전사고 직후인 2011 년 5월 한국보건사회연구원에서 실시한 조사 결과에서는 본인 및 가족 건강을 위해 비를 맞지 않도록 노력하거나 외출 후 세수 또는 샤워를 한다는 등의 외부피폭을 우려 한 예방 조치를 한다는 응답이 많았던 반면[9], 원전사고 이후 3년이 경과한 금번 조사에서는 일본산 식품의 섭취 를 자제하거나 수산물 섭취를 줄이는 등 식품을 통한 방 사능 물질 노출경로를 차단하는 조치를 주로 취하는 것 으로 나타났다.

\section{4 후쿠시마 원전사고와 방사능 관련 정보 수집경로 및 신뢰도}

일본 원전사고 및 방사능 관련 정보를 얻는 경로와 신 뢰도를 알아보기 위해 5 개 문항을 구성하였다. '일본 원
전사고 및 방사능 관련 정보가 국민에게 충분히 제공되 었다'라는 문항에 '전혀 그렇지 않다' 또는 '그렇지 않은 편이다'는 응답자가 $76.1 \%$, '그런 편이다' 또는 '매우 그 렇다라고 답한 응답자는 $23.9 \%$ 로 정보제공이 충분하지 않다고 생각하는 비율이 높았다(Table 6). 원전사고의 영향, 안전 인식도와 마찬가지로 여성과 평균연령이 낮 을수록(20-30대), 지식수준이 높을수록 관련 정보가 부족 하다고 생각하고 있었다.

'일본 원전사고에 대한 우리 정부의 조치·대응을 알고 있는가'라는 문항에는 '전혀 모른다' $15.7 \%$, '모르는 편이 다' $53.2 \%$, '알고 있는 편이다' $26.2 \%$, '매우 잘 알고 있 다' $5.0 \%$ 로 전체의 $68.9 \%$ 가 원전사고에 대한 우리 정부 의 조치 및 대응 내용을 모르고 있다고 답변하였다 (Table 7). 이러한 결과는 정부가 취한 일련의 조치에 대 해 잘 모른다고 답변한 비율(각각 $42.7 \%, 44.4 \%$ )이 가장 높았던 한국보건사회연구원, $\mathrm{Park} \mathrm{JH}$ 의 연구결과와 유사 한 것으로 나타났다[8, 9].

‘원전사고 및 방사능 관련 정보취득 경로'는 'TV 또는 케이블 방송’ $49.8 \%$, ‘인터넷’ $31.3 \%$, '신문 또는 인쇄매 체(인터넷 제외)' $13.0 \%$, '주변사람' $2.2 \%$, '정부부처 및 유관기관 홈페이지' $1.3 \%$, '홍보물' $1.0 \%$, '교육 및 세미 나' $0.5 \%$, '관련 전문서적' $0.5 \%$ 인 것으로 나타나 우리 국민들은 주로 TV 또는 인터넷을 통해 관련 정보를 취 득하고 있었고, 정부부처 및 유관기관을 통한 정보 취득 비율은 매우 낮았다(Table 8).

Table 6. Awareness on Published Information Concerning the Fukushima Nuclear Accident (\%)

\begin{tabular}{lcccc} 
& $\begin{array}{c}\text { Strongly } \\
\text { disagree }\end{array}$ & Disagree & $\begin{array}{c}\text { Agree } \\
\text { SD } \\
\text { (4 points) }\end{array}$ & $\begin{array}{c}\text { Strongly } \\
\text { agree }\end{array}$ \\
\hline $\begin{array}{l}\text { The published information about the Fukushima nuclear } \\
\text { power plant accident and radioactivity has been sufficient }\end{array}$ & 22.8 & 53.3 & 20.2 & 3.7 \\
\hline
\end{tabular}

Table 7. Awareness on the Government Response Concerning the Fukushima Nuclear Accident (\%)

\begin{tabular}{|c|c|c|c|c|c|c|}
\hline & $\begin{array}{l}\text { Strongly } \\
\text { disagree }\end{array}$ & Disagree & Agree & $\begin{array}{l}\text { Strongly } \\
\text { agree }\end{array}$ & $\begin{array}{c}\mathrm{M} \\
\text { (4 points) }\end{array}$ & $\mathrm{SD}$ \\
\hline $\begin{array}{l}\text { I know the follow-up measures and actions from the } \\
\text { government about Fukushima nuclear power plant accident }\end{array}$ & 15.7 & 53.2 & 26.2 & 5.0 & 2.21 & 0.76 \\
\hline
\end{tabular}

Table 8. Sources of Information Acquisition on the Fukushima Nuclear Accident and Radioactivity

\begin{tabular}{|c|c|c|}
\hline & $\mathrm{N}$ & $\%$ \\
\hline TV or cable TV & 299 & 49.8 \\
\hline Newspapers or media(except the Internet) & 78 & 13.0 \\
\hline The Internet(articles, blogs, tweets, etc.) & 188 & 31.3 \\
\hline Promotional materials(booklets, flyers, etc.) & 6 & 1.0 \\
\hline The government ministries and related organizations websites & 8 & 1.3 \\
\hline Training sessions and seminars & 3 & 0.5 \\
\hline Related publications & 3 & 0.5 \\
\hline Acquaintances/Relatives & 13 & 2.2 \\
\hline Other & 2 & 0.3 \\
\hline Total & 600 & 100.0 \\
\hline
\end{tabular}


Table 9. Reliability of Information Channels Concerning the Fukushima Nuclear Accident and Radioactivity

\begin{tabular}{|c|c|c|}
\hline & $\mathrm{N}$ & $\%$ \\
\hline The Government ministries(KFDS, MAFRA, MOF, etc.) & 138 & 23.0 \\
\hline Researcher in the field of nuclear energy & 55 & 9.2 \\
\hline Nuclear energy experts from Korea and abroad & 156 & 26.0 \\
\hline Environment organization/Consumer organizations & 192 & 32.0 \\
\hline Power bloggers & 33 & 5.5 \\
\hline Acquaintances/Relatives & 15 & 2.5 \\
\hline Other & 11 & 1.8 \\
\hline Total & 600 & 100.0 \\
\hline
\end{tabular}

Table 10. Effective Information Channels Concerning the Fukushima Nuclear Accident and Radioactivity

\begin{tabular}{|c|c|c|}
\hline & $\mathrm{N}$ & $\%$ \\
\hline Notification of information periodically through government ministries and related organization's websites & 101 & 16.8 \\
\hline Training sessions and seminars by experts & 99 & 16.5 \\
\hline Mass media such as news & 323 & 53.8 \\
\hline Social networking service exclusively used for information notification & 56 & 9.3 \\
\hline Development and distribution of promotional materials(booklets, flyers, etc.) & 16 & 2.7 \\
\hline Other & 5 & 0.8 \\
\hline Total & 600 & 100.0 \\
\hline
\end{tabular}

Table 11. Information Demands Concerning the Fukushima Nuclear Accident and Radioactivity

\begin{tabular}{|c|c|c|}
\hline & $\mathrm{N}$ & $\%$ \\
\hline Updates of damage control for the Fukushima nuclear power plant accident & 61 & 10.2 \\
\hline The government response concerning the Fukushima nuclear power plant accident & 93 & 15.5 \\
\hline Radioactive contamination levels and safety of foodstuffs and environment & 243 & 40.5 \\
\hline The effects of radionuclides on environment and human bodies & 126 & 21.0 \\
\hline Basic information about radioactivity & 62 & 10.3 \\
\hline Emergency response guidance for nuclear power plant accident & 13 & 2.2 \\
\hline Other & 2 & 0.3 \\
\hline Total & 600 & 100.0 \\
\hline
\end{tabular}

Table 12. Future Tasks of the Government Concerning the Fukushima Nuclear Accident

\begin{tabular}{|c|c|c|}
\hline & $\mathrm{N}$ & $\%$ \\
\hline Evaluation of local nuclear power plants and development of emergency response manual & 207 & 34.5 \\
\hline Accurate measurement of radioactivity and continuous publication of results & 158 & 26.3 \\
\hline Surveillance on radioactive contamination levels of local foods & 107 & 17.8 \\
\hline Expansion of banned food items imported from Japan & 93 & 15.5 \\
\hline $\begin{array}{l}\text { Reduction of local nuclear power plants and reconsideration on additional construction of nuclear } \\
\text { power plants }\end{array}$ & 32 & 5.3 \\
\hline Other & 3 & 0.5 \\
\hline Total & 600 & 100.0 \\
\hline
\end{tabular}

정보원의 신뢰도를 묻는 문항에서는 '환경단체 및 소 비자단체'가 $32.0 \%$ 로 가장 높았고, '원자력 분야에 종사 하는 국내·외 전문가' $26.0 \%$, '정부기관' $23.0 \%$, '원자력 분야 학자' $9.2 \%$, '인터넷 파워블로거' $5.5 \%$, '주변사람' $2.5 \%$ 순으로 나타났다(Table 9).

'원전사고 및 방사능 관련 정보를 전달하기 위한 효과 적인 방법'으로는 '뉴스, 신문 등의 언론매체를 통한 전 달'이 $53.8 \%$ 로 가장 높았고, '정부부처 및 유관기관 홈페
이지를 통한 주기적인 정보 공개’ $16.8 \%$, '관련 전문가들 을 통한 교육 또는 세미나' $16.5 \%$, '정보 제공을 위한 전 용 트위터 및 앱’ $9.3 \%$, ‘홍보물 제작 및 배포' $2.7 \%$ 등 의 순이었다(Table 10).

효과적인 정보 전달 채널, 정보 취득 방법 및 신뢰도 에 대한 3 개 문항의 결과를 종합해 보면, 현재 유관기관 홈페이지, 교육·세미나, 홍보물을 통해 주로 이루어지 고 있는 방사능 관련 정보 전달 방법의 효과에 의문점을 
제기해 볼 수 있으며, 향후에는 정보의 접근 용이성과 정보원의 신뢰성을 고려한 전략적인 정보전달 방안 마련 이 시급함을 알 수 있다.

\section{5 후쿠시마 원전사고 관련 정보제공 방향 및 향후 해 결과제}

‘후쿠시마 원전사고 및 방사능과 관련하여 가장 필요 한 정보가 무엇인지'에 대해서는 '식품 - 환경 등의 방사 능 오염 정도와 안전성' 정보가 필요하다고 답변한 응답 자가 $40.5 \%$ 로 가장 많았고, '방사능 물질이 환경 또는 인체에 미치는 영향' $21.0 \%$, '원전사고와 관련한 정부의 조치 내용' $15.5 \%$, '방사능에 대한 기본적인 지식 전달' $10.3 \%$, '일본 원전사고의 수습 진행 상황' $10.2 \%$, '원전 사고 시 대처요령' $2.2 \%$ 의 순이었다(Table 11 ).

'정부가 후쿠시마 원전사고와 관련하여 가장 먼저 해 야 할 일은 무엇인가'라는 문항에 대해서는 '국내 원전 점검 및 사고 대응 매뉴얼 관리' $34.5 \%$, '지속적이고 정 확한 방사능 검사 결과 공개' $26.3 \%$, '국내 식품에 대한 방사능 검사 실시' $17.8 \%$, '일본산 식품 수입 금지 확대' $15.5 \%$, '국내 원전 축소 및 건설 예정 원전 재검토' $5.3 \%$ 로 나타났다.

이러한 결과는 우리 국민들이 일본 원전사고로 누출 된 방사능 물질의 인체 안전성 문제에 가장 관심이 높지 만, 이를 계기로 국내 원전의 안전확보, 관리감독 문제로 까지 관심영역이 점차 확대되고 있음을 시사한다.

\section{4. 결론}

본 연구는 2011년 3월 일본에서 발생한 후쿠시마 원 전사고와 방사능에 대한 우리 국민들의 인식도 조사를 통해 정확한 정보제공 방안을 마련하고, 쌍방향 리스크 커뮤니케이션 전략 구축의 기초자료로 활용하기 위한 목 적으로 수행되었다. 인식도 확인을 위한 설문조사는 수 도권에 거주하고 있는 만 20세 이상의 성인 600명을 대 상으로 1:1 면접설문 방식으로 진행되었고, 그 결과는 다음과 같다. 방사선 및 방사능에 대한 지식을 묻는 문 항(10개 세부문항)의 답변결과를 100점 만점으로 환산했 을 때, 우리 국민들의 방사선 및 방사능 관련 기본 지식 수준은 평균 56.7점으로 낮은 편이었고, 특히 중하위권 그룹은 실제보다 자기 지식수준을 높게 평가하는 경향을 보였다. 이러한 결과는 방사선 및 방사능에 대해 잘못된 정보를 습득한 국민들이 이를 자각하지 못하고 있음을 의미하며, 방사능과 관련한 기초지식의 폭을 넓힐 수 있 는 정확한 정보제공 및 교육 강화가 필요하다는 점을 시 사한다. 대다수 국민들은 후쿠시마 원전사고로 인한 방 사능 누출이 여전히 우리나라에 영향을 미치고 있다 (92.6\%)고 생각하고 있었고, 특히 어패류 등 수산물의 안전성에 대한 불안감이 가장 높았다(52.9\%). 이러한 결 과는 최근 태풍 등의 영향으로 일본 원전인근 방사능 오 염수가 해양으로 유출되는 사건이 발생하면서 수산물의 방사능 오염을 우려한 부정적 인식의 영향인 것으로 판
단된다. 또한 국내산 식품(72.5\%)보다는 일본산 수입식 품(93.0\%)의 안전성에 더 높은 불안감을 나타내었고, 일 본 원전사고 이후 본인 및 가족의 건강을 위해 일본산 식품의 섭취를 자제하거나(34.3\%), 수산물의 섭취를 줄 이거나 피하는(19.1\%) 등 식품섭취를 통한 인체 내 방사 능 피폭을 최소화할 수 있는 조치를 우선적으로 취하고 있었다. 관련 정보제공에 대해서는 대다수 국민들이 일 본 원전사고와 방사능 오염 정보가 충분히 제공되지 않 고 있다(76.1\%)고 느끼고 있으며, 일본 원전사고에 대한 우리 정부의 조치 및 대응 내용도 대부분 모르고 있다 (68.9\%)고 답변하였다. 방사능 관련 정보의 효과적인 전 달 방법으로 뉴스 또는 신문 등의 언론 매체를 통한 전 달(53.8\%)을 꼽았으며, 정보원에 대한 신뢰도는 환경단 체 및 소비자단체(32.0\%)가 가장 높았다. 국민들이 실제 로 정보를 취득하는 경로는 TV방송(49.8\%), 인터넷 (31.3\%), 신문(13.0\%) 등의 순이었고, 정부부처 및 유관 기관 홈페이지를 통한 정보 취득은 $1.3 \%$ 에 불과했다. 현 재 식품의약품안전처 등 정부기관에서는 일본 원전사고 및 방사능 관련 정보를 주로 홈페이지를 통해 전달하고 있으나 실제로 이들 경로를 통한 국민들의 정보 습득 빈 도는 미미한 것으로 나타나 향후 개선이 필요하다. 한편 일본 원전사고 및 방사능과 관련하여 우리 국민들은 식 품 - 환경 등의 방사능 오염수준과 인체 안전성에 대한 정보제공(61.5\%)이 가장 중요하다고 생각하고 있었고, 정부가 해결해야 할 우선 과제로는 국내 원전에 대한 점 검 및 사고대응 매뉴얼 관리(34.5\%) 등을 꼽았다. 실제 로 우리 국민들이 필요로 하는 정보들 중 일부는 이미 관련 기관 홈페이지 등을 통해 공개되고 있으나 국민들 은 관련 정보가 충분히 제공되지 않고 있다고 생각하고, 정부의 조치 및 대응 내용도 잘 모르고 있는 것으로 나 타났다. 따라서 기존의 홍보방법 및 소통창구에 대한 재 평가를 통해 정보전달 방법의 개선이 필요하다. 금번 연 구 결과는 향후 방사능에 대한 국민들의 올바른 인식을 제고하고, 국내 또는 인접국가에서 유사한 사고 발생 시 효과적인 쌍방향 리스크커뮤니케이션 방안을 마련하는 데 유용한 기초자료로 활용될 수 있을 것으로 기대된다.

\section{감사의 글}

본 연구는 농림축산식품부 첨단생산기술개발사업에 의해 이루어진 것이며 연구지원에 감사드립니다.

\section{REFERENCES}

1. Byun MW. Fukushima nuclear power plant accident and food safety. Food Science and Industry. 2011;44(2):9-15.

2. Yoon HJ. Survey of radioactive contamination in agrofishery products. National Institute of Food and Drug Safety Evaluation. Korea. 14161예방안 078. Cheoungju, Republic of Korea. 2014;5-26.

3. Lee JK. Proposal for wiser control policy on radioactivity in Japanese produce and for risk communication strategy. Ministry of Food and Drug 
Safety, Cheoungju, Republic of Korea. 2013;8-94.

4. Kckendree MG, Ortega DL, Widmar NO, Wang $\mathrm{HH}$. Consumer perceptions of seafood industries in the wake of the deepwater horizon oil spill and Fukushima Daiichi nuclear disaster. Staff paper 2013-03. Michigan State University, East Lansing, MI. 2013;1-22.

5. Chio TD. Radioactive contamination of food and its risk. Bulletin of Food Technology. 2012;25(1): 75-81.

6. Son JS. Current risk communication in Republic of Korea after the Fukushima nuclear accident and effective measures for food consumers. Korea University. MS Thesis. 2014;3-5.

7. Pineda-Solano A, Carreto-Vazquez VH, Mannan MS. The Fukushima Daiichi accident and its impact on risk perception and risk communication. Chemical Engineering Transactions. 2013;31(1): 517-522.

8. Park JH. Food safety awareness of consumer in
Korea following the Fukushima nuclear accident. Korea University. MS Thesis. 2015;1-5.

9. Korea Instate for Health and Social Affairs. The effects of Japan nuclear plant accident on the health of the Korean people and countermeasures. 2011-48. Sejong, Republic of Korea. 2011;65-77.

10. Hiromi H, Yuko K, Tsutomu S. Consumer awareness and attitude on radiocesium food contamination following Fukushima incident. Journal of Disaster Research. 2013;8(7):762-772.

11. Park BJ. Analysis of Public perception on radiation: with one year after Fukushima nuclear accident. Journal of Radiation Protection. 2012;37(1):1-9.

12. Kim CS, Kim DH, Kim JH. Analysis of awareness of radiation and nuclear power plants after Fukushima nuclear accident. Journal of Korea Contents Association. 2013;13(9):281-287. 